\title{
FOREIGN DIRECT INVESTMENT, INDEKS KEMUDAHAN BERUSAHA, DAN TARIF PAJAK PENGHASILAN NEGARA-NEGARA ASEAN
}

\author{
Setiadi Alim Lim ${ }^{1 *}$ \\ ${ }^{1}$ Program Studi Akuntansi Politeknik Ubaya \\ Jalan Ngagel Jaya Selatan 169, Surabaya \\ *Corresponding Author: setiadi.alim@gmail.com
}

\begin{abstract}
The inflow of Foreign Direct Investment is needed by all countries in the world to be used as a catalyst to achieve the goals of sustainable development in all aspects of a country's life. Countries in the Southeast Asia Region that are members of ASEAN also need Foreign Direct Investment. The success of a country in attracting Foreign Direct Investment inflows is determined by many factors, including the ease of doing business and the income tax rate. In this study, a comparative study was conducted between the success of ASEAN countries in obtaining Foreign Direct Investment inflows with the success of achieving a high index of ease of doing business and the use of competitive income tax rates. The comparison was only made between 10 ASEAN member countries from 11 ASEAN member countries, because of the difficulty in collecting data from 1 other ASEAN member country, namely Timor Leste. The results showed that Singapore succeeded in attracting the largest Foreign Direct Investment inflows among other ASEAN countries, amounting to $59.10 \%$ of the total Foreign Direct Investment inflows from ASEAN countries. Singapore's success in attracting the largest Foreign Direct Investment inflow among other ASEAN countries is directly proportional to its achievement in obtaining the best ease of doing business index and the lowest income tax rate compared to other ASEAN countries. Meanwhile, for other ASEAN countries, there is no visible comparison between the success of obtaining Foreign Direct Investment with the ease of doing business index and the Income Tax rate.
\end{abstract}

Keywords: Foreign Direct Investment, ease of doing business index, Income Tax.

\begin{abstract}
ABSTRAK
Arus masuk Foreign Direct Investment dibutuhkan semua negara di dunia untuk dipakai sebagai katalisator untuk mencapai tujuan pembangunan berkelanjutan di semua aspek kehidupan suatu negara. Negara-negara di Kawasan Asia Tenggara yang tergabung dalam ASEAN juga membutuhkan Foreign Direct Investment. Keberhasilan suatu negara dalam menarik arus masuk Foreign Direct Investment ditentukan oleh banyak faktor, antara lain faktor kemudahan berusaha dan tarif
\end{abstract}


Pajak Penghasilan. Pada penelitian dilakukan studi perbandingan antara keberhasilan negara-negara ASEAN di dalam memperoleh arus masuk Foreign Direct Investment dengan keberhasilan mencapai indeks kemudahan berusaha yang tinggi dan penggunaan tarif Pajak Penghasilan yang kompetitif. Perbandingan hanya dilakukan di antara 10 negara anggota ASEAN dari 11 negara anggota ASEAN, karena kesulitan mengumpulkan data dari 1 negara anggota ASEAN lainnya, yaitu Timor Leste. Hasil penelitian menunjukkan bahwa Singapura berhasil menarik arus masuk Foreign Direct Investment terbesar di antara negara-negara ASEAN lainnya yaitu sebesar $59,10 \%$ dari jumlah keseluruhan arus masuk Foreign Direct Investment negara-negara ASEAN. Keberhasilan Singapura menarik arus masuk Foreign Direct Investment terbesar di antara negara-negara ASEAN lainnya berbanding lurus dengan prestasi mendapatkan indeks kemudahan berusaha yang terbaik dan tarif Pajak Penghasilan terendah dibandingkan dengan negara-negara ASEAN lainnya. Sedangkan untuk negara-negara ASEAN lainnya tidak terlihat adanya perbandingan lurus antara keberhasilan memperoleh Foreign Direct Investment dengan indeks kemudahan berusaha, dan tarif Pajak Penghasilan.

Kata kunci: Foreign Direct Investment, indeks kemudahan berusaha, Pajak Penghasilan.

\section{PENDAHULUAN}

Dalam menyelenggarakan kegiatan pemerintahan, setiap negara membutuhkan dana yang besar untuk membiayai pengeluaran tersebut. Untuk membiayai pengeluaran tersebut, pemerintah membutuhkan sumber penerimaan yang besar. Besarnya anggaran pengeluaran yang dibuat harus disesuaikan dengan besarnya anggaran penerimaan. Anggaran pengeluaran yang lebih besar dari pada anggaran penerimaan akan membuat terjadinya defisit keuangan yang dialami negara tersebut. Masalah defisit dalam anggaran penerimaan dan pengeluaran suatu negara memang bukan hal yang tabu. Tetapi seyogyanya defisit tersebut harus dipertimbangkan pada suatu tingkat yang wajar. Kesalahan dalam penyusunan anggaran penerimaan dan pengeluaran suatu negara akan membawa negara itu pada suatu krisis ekonomi yang akan memicu kebangkrutan ekonomi nasional.

Umumnya sumber penerimaan utama dari semua negara di seluruh dunia berasal dari sektor pajak. Dari tahun ke tahun proporsi penerimaan pajak dari jumlah seluruh penerimaan setiap negara terus meningkat. Data World Bank-a (2020) dan World Bank-b (2020) setelah diolah menunjukkan proporsi rata-rata jumlah penerimaan dunia dari sektor pajak pada tahun 1991 sebesar 62,70\% dari jumlah seluruh penerimaan. Proporsi ini kemudian menurun pada tahun 2019, di mana rata-rata jumlah penerimaan dunia dari sektor pajak menjadi $57,89 \%$ dari jumlah keseluruhan penerimaan suatu negara.

Walaupun pendapatan dari sektor pajak sudah menjadi tulang punggung utama dalam penerimaan dari suatu negara, namun setiap negara harus 
melaksanakan kebijakan perpajakan dengan penuh kehati-hatian. Masalah pajak merupakan hal yang sangat sensitif bagi investor asing untuk menanamkan modalnya di suatu negara, khususnya investasi asing yang bersifat langsung (Foreign Direct Investment/FDI). OECD (2007) menyatakan negara yang akan menarik minat investor asing untuk menanamkan modalnya dalam bentuk Foreign Direct Investment harus dapat menawarkan keuntungan lokasi yang salah satu diantaranya adalah beban pajak yang rendah. World Bank (2020) juga menetapkan masalah pembayaran pajak sebagai salah satu indikator yang dipakai menentukan kemudahan untuk berusaha.

Penerimaan dari sektor pajak dapat berasal dari Pajak Penghasilan, Pajak Penjualan, Pajak Retail, Pajak Pertambahan Nilai, dan jenis pajak lainnya. Proporsi penerimaan dari Pajak Penghasilan cukup besar. Pada tahun 2018 ratarata persentase penerimaan Pajak Penghasilan dari total penerimaan pajak sebesar $33 \%$ untuk negara-negara OECD, 25\% untuk negara-negara Amerika Latin dan Karibia, serta 37\% untuk negara-negara Afrika (OECD, 2020). Dengan melihat besarnya kontribusi dari Pajak Penghasilan terhadap seluruh penerimaan pajak, maka turun atau naiknya jumlah penerimaan Pajak Penghasilan akan berpengaruh terhadap besar kecilnya penerimaan pajak setiap negara secara keseluruhan.

Besar kecilnya jumlah penerimaan Pajak Penghasilan salah satunya ditentukan oleh besar kecilnya tarif Pajak Penghasilan yang diimplementasikan oleh setiap negara. Namun seperti halnya jenis pajak lainnya, untuk mengoptimalkan besarnya jumlah penerimaan Pajak Penghasilan tidak berarti suatu negara harus menetapkan tarif Pajak Penghasilan yang setinggi-tingginya. Banyak faktor yang harus dipertimbangkan untuk menentukan tarif Pajak Penghasilan yang tepat untuk suatu negara. Salah satunya adalah kemampuan dan kapasitas dari Wajib Pajak untuk membayar Pajak Penghasilan.

Di samping tarif, besarnya jumlah penerimaan Pajak Penghasilan ditentukan juga dengan luasnya basis pemajakan yang akan dikenakan Pajak Penghasilan. Basis pemajakan harus terus diperluas dengan menambah Wajib Pajak yang akan dikenakan Pajak Penghasilan, terutama Wajib Pajak yang potensial. Salah satu usaha untuk memperluas basis dari Wajib Pajak adalah mendatangkan investor dari luar negeri untuk menginvestasikan modalnya, khususnya untuk investasi yang bersifat langsung. Adanya investasi asing yang bersifat langsung akan meningkatkan percepatan jalannya roda perekonomian yang berarti memperluas basis yang dapat dikenakan Pajak Penghasilan. Pajak Penghasilan dapat dikenakan atas penghasilan yang diperoleh dari kegiatan usaha investor asing tersebut, penghasilan yang diperoleh oleh para pimpinan, karyawan, pekerja, pemegang saham, dan pihak lainnya.

Keberhasilan untuk menarik investasi asing ke dalam negeri mempunyai manfaat yang banyak bagi suatu negara. Di samping untuk memperluas basis pemajakan, investasi asing juga diharapkan dapat menarik tenaga kerja yang besar, mengolah sumber daya alam, alih teknologi, dan manfaat-manfaat lainnya. OECD (2019) menyatakan Foreign Direct Investment mempunyai peranan penting dalam membuat kemajuan menuju tujuan pembangunan berkelanjutan, di mana dari sudut pandang negara tuan rumah, ini dapat meningkatkan pertumbuhan dan inovasi, menciptakan pekerjaan berkualitas dan 
mengembangkan sumber daya manusia, meningkatkan standar hidup dan kelestarian lingkungan. Menurut Bayraktar (2013) Foreign Direct Investment, terutama aliran dana masuk, dipandang sebagai sumber penyangga teknologi yang penting, peningkatan efisiensi, dan pertumbuhan.

Dalam membangun ekonomi nasionalnya, umumnya suatu negara membutuhkan investasi asing, khususnya negara-negara yang sedang berkembang. Mengingat terbatasnya jumlah investasi asing yang ditawarkan dan banyaknya jumlah permintaan investasi asing yang dibutuhkan terutama oleh negara-negara berkembang, maka sesuai dengan hukum permintaan dan penawaran, akan terjadi persaingan antara negara-negara yang membutuhkan investasi. Masing-masing negara akan berusaha untuk menarik investor dengan berbagai macam cara. Bayraktar (2013) menyatakan ada beberapa faktor yang mungkin dipertimbangkan oleh investor dalam menanamkan investasinya pada suatu negara, antara lain biaya tenaga kerja, jumlah tenaga kerja manusia, pengembalian investasi, keterbukaan perdagangan, keterbukaan keuangan, ukuran negara, kekayaan sumber daya alam, penentu makroekonomi dan politik, pajak, serta iklim investasi di negara tempat investasi ditempatkan.

Kebutuhan investasi asing juga berlaku pada negara-negara di Kawasan Asia Tenggara yang tergabung dalam komunitas ASEAN (Association of Southeast Asian Nations). Masing-masing negara-negara ASEAN berusaha agar negaranya menjadi negara yang paling "ease of doing business" dalam rangka menarik investasi asing dengan memenuhi kriteria-kriteria yang diinginkan oleh investor. Pada penelitian ini akan dilakukan studi perbandingan mengenai indeks kemudahan berusaha dan tarif Pajak Penghasilan yang diterapkan di negaranegara ASEAN dihubungkan dengan besarnya investasi asing dalam bentuk Foreign Direct Investment. Besarnya Foreign Direct Investment akan diambil dari data UNCTAD (2020). Data indeks kemudahan berusaha akan mengambil acuan data yang dipublikasikan oleh World Bank (2020). Sedangkan untuk tarif Pajak Penghasilan akan diambil data tarif Pajak Penghasilan rata-rata (TPRR)/Average Tax Rate (ATR). Untuk menghitung besarnya tarif Pajak Penghasilan rata-rata (TPRR)/Average Tax Rate (ATR) akan digunakan perhitungan dari Bonu and Motau (2009).

\section{TINJAUAN PUSTAKA}

\section{Foreign Direct Investment}

Setiap negara umumnya membutuhkan investasi asing untuk membantu mengakselerasi kegiatan ekonominya dalam rangka mencapai target pertumbuhan ekonomi yang diinginkan. Investasi asing merupakan katalisator dalam rangka pembangunan ekonomi suatu negara. Bukan hanya negara berkembang yang membutuhkan investasi asing, negara-negara maju juga membutuhkan investasi asing. Namun seperti yang dikatakan oleh Bayraktar (2013) jumlah investasi yang masuk dalam bentuk Foreign Direct Investment di negara-negara berkembang terus meningkat dari waktu ke waktu, sedangkan untuk negara-negara maju terus menurun.

Setiap negara harus memahami bahwa dampak dari Foreign Direct Investment dari setiap investor terhadap kemajuan perekonomian negaranya 
berbeda-beda. Menurut Lejárraga and Ragoussis (2018) selain untuk menarik investasi asing langsung (Foreign Direct Investment) yang lebih tinggi, negara berkembang juga semakin peduli dengan investasi yang membantu memajukan pembangunan sosio-ekonomi dan kelestarian lingkungan. Seruan untuk "Foreign Direct Investment berkualitas" atau "Foreign Direct Investment yang tepat" mencerminkan keinginan yang lebih dari sekadar menarik modal asing. Modal asing diharapkan dapat membantu menciptakan pekerjaan, meningkatkan keterampilan dan pengetahuan negara host, memberikan lebih banyak peluang bagi perempuan dan perusahaan domestik untuk berkembang, serta meningkatkan rasa hormat terhadap lingkungan.

Saat ini negara-negara berkembang sudah memperhatikan kualitas dari investasi yang akan masuk. OECD (2019) menyatakan bahwa kualitas Foreign Direct Investment ditentukan oleh jenis Foreign Direct Investment, kebijakan dan kondisi negara yang menerima arus masuk investasi asing (host country) seperti terlihat pada Gambar 1 di bawah ini.

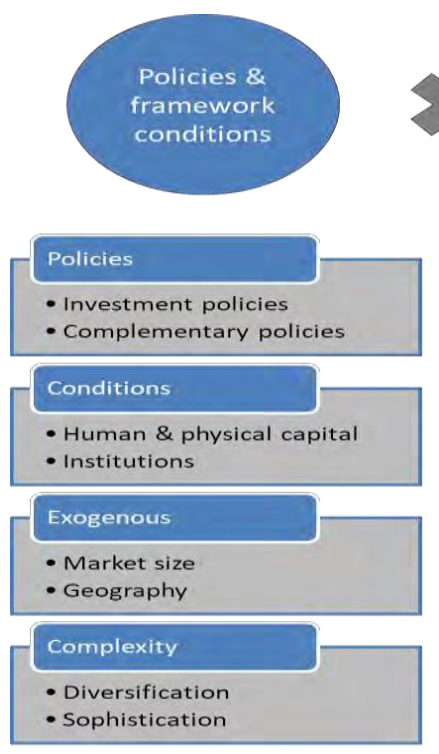

Sumber: OECD (2019)
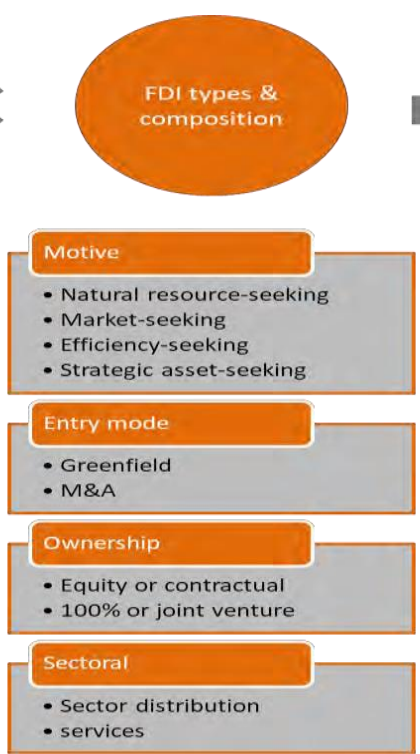

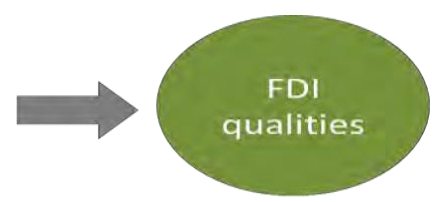

\section{Prosperity}

- Productivity \& innovation

- Employment and job quality

\begin{tabular}{l} 
People \\
- Skills \\
- Gender equality \\
\hline Planet \\
- Carbon footprint \& \\
renewable energy
\end{tabular}

\section{Gambar 1 \\ Kualitas Foreign Direct Investment Dicapai Melalui Jenis Foreign Direct Investment, Kebijakan, dan Kondisi Negara Host}

Jumlah Foreign Direct Investment ini dari tahun ke tahun mengalami fluktuasi. Dari tahun yang satu ke tahun berikutnya kadang mengalami kenaikan, tetapi kadang juga mengalami penurunan. Namun dalam jangka panjang jumlah Foreign Direct Investment menunjukkan trend yang meningkat. Pada tahun 2018 arus masuk Foreign Direct Investment dunia sebesar US\$ 1.495 miliar yang kemudian meningkat pada tahun 2019 menjadi sebesar US\$ 1.540 miliar (UNCTAD, 2020). Negara-negara yang termasuk kelompok 20 negara yang mempunyai arus masuk Foreign Direct Investment terbesar pada tahun 2019 seperti terlihat pada Tabel 1. 
Tabel 1

Kelompok 20 Negara dengan Arus Masuk Foreign Direct Investment Terbesar Tahun 2019

\begin{tabular}{|c|l|c|}
\hline Peringkat & \multicolumn{1}{|c|}{ Nama Negara } & Nilai dalam Miliar US\$ \\
\hline 1. & Amerika Serikat & 246 \\
\hline 2. & China & 141 \\
\hline 3. & Singapura & 92 \\
\hline 4. & Belanda & 84 \\
\hline 5. & Irlandia & 78 \\
\hline 6. & Brasil & 72 \\
\hline 7. & Hongkong & 68 \\
\hline 8. & United Kingdom & 59 \\
\hline 9. & India & 51 \\
\hline 10. & Kanada & 50 \\
\hline 11. & Jerman & 36 \\
\hline 12. & Australia & 36 \\
\hline 13. & Perancis & 34 \\
\hline 14. & Meksiko & 33 \\
\hline 15. & Rusia & 32 \\
\hline 16. & Italia & 27 \\
\hline 17. & Cyprus & 24 \\
\hline 18. & Indonesia & 23 \\
\hline 19. & Swedia & 21 \\
\hline 20. & Israel & 18 \\
\hline
\end{tabular}

Sumber: UNCTAD (2020)

\section{Kemudahan Berusaha}

Para investor asing dalam memilih negara tempat untuk menanamkan investasinya dalam bentuk Foreign Direct Investment umumnya akan mempertimbangkan prospek pengembalian dan imbalan, serta risiko dari investasi yang akan ditanamkannya. Di samping itu investor asing juga akan mempertimbangkan kemudahan, fasilitas, dan infrastruktur yang tersedia di negara di mana investor asing akan menanamkan investasinya. Kemudahan untuk berusaha yang dikenal dengan istilah ease doing business umumnya dijadikan salah satu pedoman bagi investor asing untuk menanamkan investasinya di suatu negara.

Setiap tahun World Bank menerbitkan indeks kemudahan berusaha dalam bentuk skor penilaian serta peringkat/ranking kemudahan berusaha dari masingmasing negara. Pengusaha/investor mengambil keputusan investasi masingmasing di suatu negara berdasarkan peringkat negara tersebut dalam laporan kemudahan berusaha (Abdin, 2019). Untuk menentukan skor kemudahan berusaha ini, World Bank menggunakan beberapa indikator yang selalu diperbahurui. Indikator yang dipakai oleh World Bank untuk menentukan skor kemudahan berusaha pada tahun 2020 seperti terlihat pada Gambar 2 di bawah ini. 


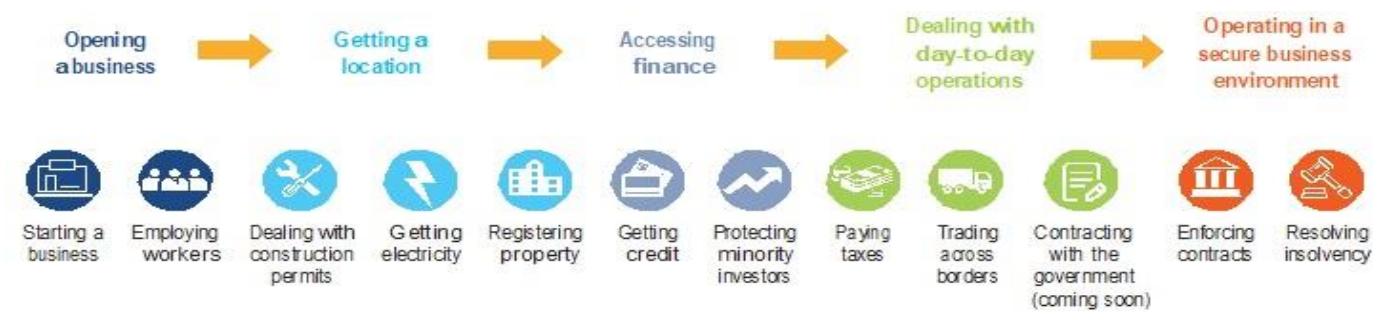

Sumber: World Bank (2020)

Gambar 2

Indikator Kemudahan Berusaha

Berdasarkan indikator tersebut telah dihitung skor kemudahan berusaha untuk masing-masing negara. Data skor kemudahan berusaha 10 negara dengan skor yang tertinggi pada tahun 2020 terlihat di Tabel 2.

Tabel 2

Daftar 10 Negara dengan Skor Kemudahan Berusaha Tertinggi

Tahun 2020

\begin{tabular}{|c|l|c|}
\hline Peringkat & \multicolumn{1}{|c|}{ Nama Negara } & $\begin{array}{c}\text { Skor Kemudahan } \\
\text { Berusaha }\end{array}$ \\
\hline 1. & New Zealand & 86,8 \\
\hline 2. & Singapura & 86,2 \\
\hline 3. & Hongkong & 85,3 \\
\hline 4. & Denmark & 85,3 \\
\hline 5. & Korea Selatan & 84,0 \\
\hline 6. & Amerika Serikat & 84,0 \\
\hline 7. & Georgia & 83,7 \\
\hline 8. & United Kingdom & 83,5 \\
\hline 9. & Norwegia & 82,6 \\
\hline 10. & Swedia & 82,0 \\
\hline & Skor Tertinggi & $\mathbf{8 6 , 8}$ \\
\hline & Skor Terendah & $\mathbf{2 0 , 0}$ \\
\hline
\end{tabular}

Sumber: World Bank (2020)

World Bank (2020) menghitung skor kemudahan berusaha berdasarkan penilaian pada 12 indikator. Salah satu indikator tersebut adalah masalah pajak. Masalah yang berkaitan dengan pajak antara lain adalah tarif pajak. Djankov et al. (2010) menyatakan bahwa pajak di negara-negara non-OECD mempengaruhi arus masuk Foreign Direct Investment, tetapi pajak tidak berpengaruh signifikan terhadap Foreign Direct Investment di negara-negara OECD. Pendapat Djankov et al. (2010) ini dipertegas lagi oleh Esteller-Moré et al. (2020) yang menyatakan pajak di negara tuan rumah sangat penting bagi arus masuk Foreign Direct Investment, tetapi hanya untuk negara-negara non-OECD. Misalnya dengan menaikkan tarif Pajak Penghasilan Badan efektif tahun pertama sebesar $10 \%$ mengurangi arus masuk Foreign Direct Investment sebesar 3,4\% menjadi 1,9\% di negara-negara non-OECD, dan efeknya nol untuk negara-negara OECD. 


\section{Pajak Penghasilan}

Secara umum pajak yang diberlakukan di banyak negara terdiri dari 2 kelompok besar, yaitu Pajak Tidak Langsung dan Pajak Langsung. Pajak Tidak Langsung dapat berupa Pajak Penjualan, Pajak Retail, Pajak Pertambahan Nilai, atau lainnya. Untuk Pajak Langsung yang terbesar jumlahnya adalah Pajak Penghasilan. Pajak Penghasilan adalah pajak yang dipungut atas penghasilan yang diterima atau diperoleh oleh Wajib Pajak. Pajak Penghasilan ini dapat dibedakan atas Pajak Penghasilan Orang Pribadi dan Pajak Penghasilan Badan.

Setiap negara akan mengambil kebijakan yang berbeda-beda mengenai tarif Pajak Penghasilan yang akan diimplementasikan, tergantung pada situasi dan kondisi negara yang bersangkutan. Di samping itu setiap negara juga perlu mempertimbangkan tujuan untuk menarik investor asing dalam menanamkan modalnya di negara tersebut pada saat menentukan tarif Pajak Penghasilan yang akan diberlakukan. Tarif Pajak Penghasilan yang rendah merupakan salah satu daya tarik bagi investor asing untuk menginvestasikan dananya. Berikut pada Tabel 3 ditunjukkan tarif Pajak Penghasilan rata-rata per kelompok negara.

Tabel 3

Tarif Pajak Penghasilan Badan Rata-Rata per Kelompok Negara

Tahun 2020

\begin{tabular}{|c|c|c|c|c|}
\hline No. & $\begin{array}{c}\text { Kelompok } \\
\text { Negara }\end{array}$ & $\begin{array}{c}\text { Tarif Rata- } \\
\text { Rata }\end{array}$ & $\begin{array}{c}\text { Tarif Rata- } \\
\text { Rata } \\
\text { Berdasarkan } \\
\text { PDB }\end{array}$ & $\begin{array}{c}\text { Jumlah } \\
\text { Negara }\end{array}$ \\
\hline 1. & Eropa & $19,99 \%$ & $24,61 \%$ & 39 \\
\hline 2. & Asia & $20,06 \%$ & $25,37 \%$ & 46 \\
\hline 3. & EU27 & $21,47 \%$ & $26,46 \%$ & 27 \\
\hline 4. & OECD & $23,51 \%$ & $26,30 \%$ & 37 \\
\hline 5. & Oceania & $23,75 \%$ & $29,74 \%$ & 8 \\
\hline 6. & Amerika Utara & $26,06 \%$ & $26,13 \%$ & 22 \\
\hline 7. & G20 & $26,96 \%$ & $26,77 \%$ & 19 \\
\hline 8. & G7 & $27,24 \%$ & $26,95 \%$ & 7 \\
\hline 9. & BRICS & $27,40 \%$ & $26,49 \%$ & 5 \\
\hline 10. & Amerika Selatan & $27,54 \%$ & $31,83 \%$ & 12 \\
\hline 11. & Afrika & $28,50 \%$ & $28,16 \%$ & 50 \\
\hline 12. & Dunia & $23,85 \%$ & $25,85 \%$ & 177 \\
\hline
\end{tabular}

Sumber: Asen (2020)

\section{METODE PENELITIAN}

Penelitian yang dilakukan merupakan penelitian yang bersifat deskriptif. Pada penelitian ini akan dilakukan studi perbandingan besarnya arus masuk Foreign Direct Investment dengan skor kemudahan berusaha dan besarnya tarif Pajak Penghasilan rata-rata yang diterapkan di negara-negara ASEAN. Untuk melakukan perbandingan akan dilakukan pemeringkatan besarnya arus masuk Foreign Direct Investment, kemudahan berusaha, dan tarif Pajak Penghasilan rata- 
rata. Setelah itu baru dilakukan analisis dan pembahasan dari hasil-hasil pemeringkatan tersebut.

Data yang digunakan adalah data sekunder yang diperoleh dari berbagai sumber. Penelitian ini menggunakan data 10 negara anggota ASEAN dari jumlah total negara anggota ASEAN sebanyak 11 negara. Negara-negara yang digunakan datanya untuk analisis adalah Brunei, Filipina, Indonesia, Kamboja, Laos, Malaysia, Myanmar, Singapura, Thailand, dan Vietnam. Sedangkan 1 negara anggota ASEAN lainnya yaitu Timor Leste tidak diikutsertakan dalam penelitian, karena kesulitan untuk memperoleh datanya.

\section{Data Foreign Direct Investment Negara-Negara ASEAN}

Untuk negara-negara ASEAN jumlah Foreign Direct Investment meningkat dari tahun 2000 yang berjumlah sebesar US\$21,8 miliar menjadi sebesar US\$ 160,6 miliar pada tahun 2019 (ASEAN Secretariat, 2020). Data besarnya Foreign Direct Investment di negara-negara ASEAN seperti yang terlihat pada Tabel 4.

Tabel 4

Besarnya Arus Masuk Foreign Direct Investment Negara-Negara ASEAN Tahun 2019

\begin{tabular}{|c|c|c|c|}
\hline Peringkat & Nama Negara & $\begin{array}{c}\text { Nilai dalam Juta } \\
\text { US\$ }\end{array}$ & $\begin{array}{c}\text { Persentase dari } \\
\text { Total ASEAN }\end{array}$ \\
\hline 1. & Singapura & 92.081 & $59,10 \%$ \\
\hline 2. & Indonesia & 23.429 & $15,04 \%$ \\
\hline 3. & Vietnam & 16.120 & $10,35 \%$ \\
\hline 4. & Malaysia & 7.650 & $4,91 \%$ \\
\hline 5. & Filipina & 4.996 & $3,20 \%$ \\
\hline 6. & Thailand & 4.146 & $2,66 \%$ \\
\hline 7. & Kamboja & 3.706 & $2,38 \%$ \\
\hline 8. & Myanmar & 2.766 & $1,77 \%$ \\
\hline 9. & Laos & 557 & $0,36 \%$ \\
\hline 10. & Brunei & 275 & $0,18 \%$ \\
\hline 11. & Timor Leste & 75 & $0,05 \%$ \\
\hline \multicolumn{2}{|c|}{ Total Negara ASEAN } & 155.801 & $100 \%$ \\
\hline \multicolumn{2}{|c|}{ Rata-Rata Negara ASEAN } & 14.164 & \\
\hline \multicolumn{2}{|c|}{ Total Dunia } & $\mathbf{1 . 5 3 9 . 8 8 0}$ & \\
\hline \multicolumn{2}{|c|}{ Total Negara Berkembang } & 684.273 & \\
\hline \multicolumn{2}{|c|}{ Total Negara Berkembang di Asia } & 473.898 & \\
\hline
\end{tabular}

Sumber: UNCTAD (2020)

\section{Data Indeks Kemudahan Berusaha Negara-Negara ASEAN}

Berdasarkan data yang diterbitkan oleh World Bank (2020) dapat disusun peringkat kemudahan berusaha negara-negara ASEAN dan skor (indeks) yang diperoleh. Peringkat dan skor kemudahan berusaha untuk negara-negara ASEAN pada tahun 2020 seperti terlihat pada Tabel 5. 
Tabel 5

Peringkat dan Skor Kemudahan Berusaha Negara-Negara ASEAN Tahun 2020

\begin{tabular}{|c|c|l|c|}
\hline $\begin{array}{c}\text { Peringkat } \\
\text { ASEAN }\end{array}$ & $\begin{array}{c}\text { Peringkat } \\
\text { Dunia }\end{array}$ & \multicolumn{1}{|c|}{ Nama Negara } & $\begin{array}{c}\text { Skor Kemudahan } \\
\text { Berusaha }\end{array}$ \\
\hline 1. & 2. & Singapura & 86,2 \\
\hline 2. & 12. & Malaysia & 81,5 \\
\hline 3. & 21. & Thailand & 80,1 \\
\hline 4. & 66. & Brunei & 70,1 \\
\hline 5. & 70. & Vietnam & 69,8 \\
\hline 6. & 73. & Indonesia & 69,6 \\
\hline 7. & 95. & Filipina & 62,8 \\
\hline 8. & 144. & Kamboja & 53,8 \\
\hline 9. & 154. & Laos & 50,8 \\
\hline 10. & 165. & Myanmar & 46,8 \\
\hline 11. & 181. & Timor Leste & 39,4 \\
\hline & $\mathbf{8 9 .}$ & Rata-Rata ASEAN & $\mathbf{6 4 , 6 3}$ \\
\cline { 2 - 4 } & $\mathbf{1}$ & Tertinggi Dunia & $\mathbf{8 6 , 8}$ \\
\cline { 2 - 4 } & $\mathbf{1 9 0}$ & Terendah Dunia & $\mathbf{2 0 , 0}$ \\
\hline
\end{tabular}

Sumber: World Bank (2020)

\section{Tarif Pajak Penghasilan Negara-Negara ASEAN}

Pajak Penghasilan dapat dibedakan atas Pajak Penghasilan Orang Pribadi dan Pajak Penghasilan Badan. Untuk negara-negara ASEAN, tarif Pajak Penghasilan Orang Pribadi dan Tarif Pajak Penghasilan Badan nampak seperti terlihat pada Tabel 6 .

Tabel 6

Tarif Pajak Penghasilan Negara-Negara ASEAN

Tahun 2018

\begin{tabular}{|c|l|c|c|c|c|}
\hline \multirow{2}{*}{ No. } & \multirow{2}{*}{$\begin{array}{c}\text { Nama } \\
\text { Negara }\end{array}$} & \multicolumn{3}{|c|}{ Tarif Pajak Penghasilan Orang Pribadi } & $\begin{array}{c}\text { Tarif Pajak } \\
\text { Penghasilan } \\
\text { Badan (TPPB) **) }\end{array}$ \\
\cline { 3 - 6 } & & $0 \%$ & $0 \%$ & 0 & $18,5 \%$ \\
\hline 1. & Brunei & $0 \%$ & $35 \%$ & 6 & $30 \%$ \\
\hline 2. & Filipina & $5 \%$ & $30 \%$ & 4 & $22 \% * * *)$ \\
\hline 3. & Indonesia & $0 \%$ & $20 \%$ & 5 & $20 \%$ \\
\hline 4. & Kamboja & $0 \%$ & $24 \%$ & 7 & $24 \%$ \\
\hline 5. & Laos & $0 \%$ & $28 \%$ & 11 & $25 \%$ \\
\hline 6. & Malaysia & $0 \%$ & $25 \%$ & 6 & $17 \%$ \\
\hline 7. & Myanmar & $0 \%$ & $22 \%$ & 8 & $20 \%$ \\
\hline 8. & Singapura & $0 \%$ & $35 \%$ & 7 & $20 \%$ \\
\hline 9. & Thailand & $5 \%$ & $35 \%$ & $7 * *)$ & $22,05 \%$ \\
\hline 10. & Vietnam & $1,11 \% * * *)$ & $28,22 \% * * *)$ & & \\
\hline & Rata-Rata & & & & \\
\hline
\end{tabular}

Sumber: Shira \& Associates (2018) 
*) $\quad$ BBTPPMOP = Batas Bawah Tarif Pajak Penghasilan Marginal Orang Pribadi BATPPMOP $=$ Batas Atas Tarif Pajak Penghasilan Marginal Orang Pribadi

**) TPPB = Tarif Pajak Penghasilan Badan

***) Rata-Rata di luar Brunei

****) Telah disesuaikan dengan tarif terbaru tahun 2020.

\section{HASIL PENELITIAN DAN PEMBAHASAN}

Berdasarkan data pada Tabel 6 akan dihitung tarif Pajak Penghasilan Orang Pribadi rata-rata (TPPOPR) dan tarif Pajak Penghasilan rata-rata (TPPR). Untuk menghitung besarnya TPPOPR dan TPPR akan digunakan rumus yang dipakai oleh Bonu and Motau (2009) dengan uraian sebagai berikut:

ㄱ $\mathrm{TPPOPR}=(\mathrm{BBTPPMOP}+\mathrm{BATPPMOP}) / 2$

口 $\mathrm{TPPR}=(\mathrm{TPPOPR}+\mathrm{TPPB}) / 2$

Dengan menggunakan data dari Tabel 6 dapat dihitung TPPOPR dan TPPR dari negara-negara ASEAN seperti terlihat pada Tabel 7.

Tabel 7

Perhitungan Tarif Pajak Penghasilan Orang Pribadi Rata-Rata (TPPOPR) dan Tarif Pajak Penghasilan Rata-Rata (TPPR)

\begin{tabular}{|c|l|c|c|c|c|}
\hline No. & $\begin{array}{c}\text { Nama } \\
\text { Negara }\end{array}$ & TPPOPR & TPPB & TPPR & $\begin{array}{c}\text { Peringkat } \\
\text { Berdasarkan } \\
\text { TPPR }\end{array}$ \\
\hline 1. & Brunei & $0,00 \%$ & $18,5 \%$ & $9,25 \%$ & 1 \\
\hline 2. & Filipina & $17,50 \%$ & $30 \%$ & $23,75 \%$ & 9 \\
\hline 3. & Indonesia & $17,50 \%$ & $22 \%$ & $19,75 \%$ & 7 \\
\hline 4. & Kamboja & $10,00 \%$ & $20 \%$ & $15,00 \%$ & 3 \\
\hline 5. & Laos & $12,00 \%$ & $24 \%$ & $18,00 \%$ & 4 \\
\hline 6. & Malaysia & $14,00 \%$ & $24 \%$ & $19,00 \%$ & 6 \\
\hline 7. & Myanmar & $12,50 \%$ & $25 \%$ & $18,75 \%$ & 5 \\
\hline 8. & Singapura & $11,00 \%$ & $17 \%$ & $14,00 \%$ & 2 \\
\hline 9. & Thailand & $17,50 \%$ & $20 \%$ & $18,75 \%$ & 5 \\
\hline 10. & Vietnam & $20,00 \%$ & $20 \%$ & $20,00 \%$ & 8 \\
\hline & Rata-Rata & $\mathbf{1 3 , 2 0 \%}$ & $\mathbf{2 2 , 0 5 \%}$ & $\mathbf{1 7 , 6 3 \%}$ & \\
\hline
\end{tabular}

Berikut ini akan disusun daftar mengenai peringkat arus masuk Foreign Direct Investment, peringkat kemudahan berusaha, dan peringkat tarif Pajak Penghasilan rata-rata untuk negara-negara ASEAN seperti terlihat pada Tabel 8. Peringkat Foreign Direct Investment akan disusun berdasarkan jumlah arus masuk Foreign Direct Investment pada tahun 2019 yang diurutkan dari jumlah tertinggi sampai dengan terendah. 
Tabel 8

Peringkat Foreign Direct Investment (FDI), Peringkat Kemudahan Berusaha, dan Peringkat Tarif Pajak Penghasilan Rata-Rata (TPPR)

Negara-Negara ASEAN

\begin{tabular}{|c|l|c|c|c|c|c|}
\hline $\begin{array}{c}\text { No. } \\
(\mathbf{1})\end{array}$ & \multicolumn{1}{|c|}{$\begin{array}{c}\text { Nama } \\
\text { Negara }\end{array}$} & $\begin{array}{c}\text { Peringkat } \\
\text { Foreign } \\
\text { Direct } \\
\text { Investment } \\
\mathbf{( 3 )}\end{array}$ & $\begin{array}{c}\text { Peringkat } \\
\text { Kemudahan } \\
\text { Berusaha } \\
\mathbf{( 4 )}\end{array}$ & $\begin{array}{c}\text { Peringkat } \\
\text { Tarif Pajak } \\
\text { Penghasilan } \\
\text { Rata-rata } \\
\mathbf{( 5 )}\end{array}$ & $\begin{array}{c}\text { Jumlah } \\
\text { Peringkat } \\
\text { Kemudahan } \\
\text { Berusaha dan } \\
\text { Tarif Pajak } \\
\text { Penghasilan } \\
\text { Rata-rata } \\
(\mathbf{6})=(4)+(5)\end{array}$ & $\begin{array}{c}\text { Peringkat } \\
\text { Berdasarkan } \\
\text { Jumlah Peringkat } \\
\text { Kemudahan } \\
\text { Berusaha dan } \\
\text { Tarif Pajak } \\
\text { Penghasilan } \\
(\mathbf{7})\end{array}$ \\
\hline 1. & Singapura & 1 & 1 & 2 & 3 & 1 \\
\hline 2. & Indonesia & 2 & 6 & 7 & 13 & 5 \\
\hline 3. & Vietnam & 3 & 5 & 8 & 13 & 5 \\
\hline 4. & Malaysia & 4 & 2 & 6 & 8 & 3 \\
\hline 5. & Filipina & 5 & 7 & 9 & 16 & 3 \\
\hline 6. & Thailand & 6 & 3 & 5 & 3 & 4 \\
\hline 7. & Kamboja & 7 & 8 & 3 & 11 & 6 \\
\hline 8. & Myanmar & 8 & 10 & 5 & 15 & \\
\hline 9. & Laos & 9 & 9 & 4 & 13 & 2 \\
\hline 10. & Brunei & 10 & 4 & 1 & 5 & \\
\hline
\end{tabular}

Penjelasan mengenai Foreign Direct Investment, indeks kemudahan berusaha, dan tarif Pajak Penghasilan untuk masing-masing negara ASEAN akan diuraikan di bawah ini.

\section{Singapura}

Tabel 8 menunjukkan Singapura menduduki peringkat 1 di negara-negara ASEAN dalam hal jumlah arus masuk Foreign Direct Investment. Hal ini dapat dipahami mengingat bahwa Singapura juga menduduki peringkat 1 untuk kemudahan berusaha dan menduduki peringkat 2 untuk tarif Pajak Penghasilan rata-rata, sehingga apabila peringkat kemudahan berusaha dan peringkat tarif Pajak Penghasilan rata-rata dijumlah akan diperoleh angka 3 yang menunjukkan bahwa nilai penjumlahan peringkat Singapura masih yang terendah dibandingkan dengan negara-negara ASEAN lainnya atau dapat disebut berada pada peringkat 1 .

Keberhasilan Singapura untuk menarik arus masuk Foreign Direct Investment yang besar dengan persentase $59,10 \%$ dari seluruh arus masuk Foreign Direct Investment negara-negara ASEAN terutama ditunjang dari kesuksesan Singapura menciptakan suatu iklim usaha yang sangat kondusif. Di samping itu dari sektor perpajakan, Singapura juga telah menetapkan tarif Pajak Penghasilan yang sangat rendah dan sangat kompetitif dibandingkan dengan negara-negara ASEAN lainnya. Prestasi fenomenal Singapura tidak hanya terbatas di kelompok negara ASEAN, tetapi prestasinya sudah mendunia. Untuk keberhasilan menarik arus masuk Foreign Direct Investment, Singapura berada di peringkat 3 dunia dan untuk keberhasilan kemudahan berusaha Singapura berada pada peringkat 2 dunia. Keberhasilan Singapura dalam menarik arus masuk Foreign Direct Investment yang sangat besar berbanding lurus dengan prestasinya dalam 
mencapai indeks kemudahan berusaha yang tinggi dan kebijakannya untuk menerapkan tarif Pajak Penghasilan yang rendah.

\section{Indonesia}

Indonesia tercatat sebagai negara dengan peringkat 2 dalam perolehan arus masuk Foreign Direct Investment di antara negara-negara ASEAN. Ini suatu prestasi yang sangat bagus, tetapi jika dilihat dari peringkat kemudahan berusaha Indonesia hanya berada di peringkat 6. Di samping itu jika dilihat dari sudut tarif Pajak Penghasilan rata-rata, Indonesia juga masih tertinggal dibandingkan negaranegara ASEAN lainnya dengan hanya menempati peringkat 7. Bila digabung peringkat kemudahan berusaha dan tarif Pajak Penghasilan rata-rata, Indonesia berada di peringkat 5 bersama dengan Vietnam dan Laos. Meskipun sudah cukup berhasil di dalam menarik arus masuk Foreign Direct Investment dibandingkan dengan negara-negara ASEAN lainnya, namun harus diingat jika ditinjau dari peringkat kemudahan berusaha dan peringkat tarif Pajak Penghasilan rata-rata kinerja Indonesia tidak menggembirakan dibandingkan dengan negara-negara ASEAN lainnya.

Oleh karena itu Indonesia harus bekerja keras untuk mengejar ketertinggalan untuk meningkatkan iklim kemudahan berusaha yang hanya berada di peringkat 6 ASEAN, dan peringkat 73 dunia. Indonesia harus berusaha mencapai semua indikator yang ditetapkan dalam penilaian iklim kemudahan berusaha. Langkah paling sederhana yang dapat dilakukan Indonesia adalah dengan melihat apa yang telah dikerjakan negara tetangga Singapura yang telah berprestasi dunia untuk digunakan sebagai benchmarking. Untuk tarif Pajak Penghasilan, Indonesia sudah menetapkan akan menurunkan tarif Pajak Penghasilan Badan dari 22\% menjadi 20\% mulai tahun 2022. Namun perlu dipertimbangkan lagi untuk menurunkan kembali tarif Pajak Penghasilan Badan ini ke tarif di bawah 20\%, mengingat Singapura sebagai negara yang bisa digunakan sebagai benchmarking menggunakan tarif Pajak Penghasilan Badan sebesar 17\%. Sedangkan untuk tarif Pajak Penghasilan Orang Pribadi, Indonesia dapat mempertimbangkan untuk menetapkan batas bawah tarif Pajak Penghasilan Marginal Orang Pribadi dari 5\% menjadi 0\%, mengingat bahwa hampir semua negara-negara di ASEAN menetapkan tarif 0\%. Di samping itu, Indonesia juga perlu mempertimbangkan untuk menurunkan batas atas tarif Pajak Penghasilan Marginal Orang Pribadi sebesar 30\% ke tarif antara 20\%-25\%, mengingat beberapa negara di ASEAN menggunakan tarif 25\% ke bawah.

\section{Vietnam}

Vietnam dalam urutan perolehan arus masuk Foreign Direct Investment berada di peringkat 3. Situasi yang dialami Vietnam hampir sama dengan Indonesia. Vietnam memperoleh arus masuk Foreign Direct Investment yang cukup besar di antara sesama negara-negara ASEAN. Namun jika dilihat dari skor angka kemudahan berusaha, Vietnam hanya berada di peringkat 5 atau 1 peringkat lebih baik dari Indonesia. Demikian pula jika dilihat dari tarif Pajak Penghasilan rata-rata, Vietnam hanya berada di peringkat 8 . Sedangkan jika peringkat 
kemudahan berusaha dan peringkat tarif Pajak Penghasilan rata-rata digabungkan, Vietnam hanya berada di peringkat 5 bersama Indonesia dan Laos.

Dalam kondisi demikian, walaupun Vietnam telah berhasil mendapatkan arus masuk Foreign Direct Investment yang cukup besar, namun perlu memperbaiki iklim kemudahan berusaha dan tarif Pajak Penghasilan rata-rata, sehingga jumlah arus masuk Foreign Direct Investment diharapkan dapat meningkat lagi. Guna memperbaiki iklim kemudahan berusaha, Vietnam dapat menggunakan Singapura sebagai benchmarking. Berkaitan dengan tarif Pajak Penghasilan Badan, Vietnam sudah menetapkan tarif yang sangat kompetitif sebesar 20\%, namun Vietnam dapat mempertimbangkan untuk menurunkannya lagi, mengingat Brunei dan Singapura hanya mengenakan tarif Pajak Penghasilan Badan masing-masing sebesar 18,5\% dan 17\%. Untuk Pajak Penghasilan Orang Pribadi, sebaiknya Vietnam menurunkan batas bawah tarif Pajak Penghasilan Marginal Orang Pribadi dari 5\% menjadi 0\%, mengingat bahwa hampir semua negara-negara di ASEAN menetapkan tarif 0\%. Sedangkan untuk batas atas tarif Pajak Penghasilan Marginal Orang Pribadi, Vietnam dapat mempertimbangkan untuk menurunkan tarifnya dari 35\% menjadi tarif antara $20 \%-25 \%$, mengingat beberapa negara di ASEAN menggunakan tarif $25 \%$ ke bawah.

\section{Malaysia}

Malaysia berada pada peringkat 4 di antara negara-negara ASEAN yang mendapatkan arus masuk Foreign Direct Investment. Jika dilihat dari skor kemudahan berusaha, Malaysia berada di peringkat 2. Sedangkan bila ditinjau dari tarif Pajak Penghasilan rata-rata Malaysia berada di peringkat 6. Secara keseluruhan jika peringkat kemudahan berusaha dan peringkat tarif Pajak Penghasilan rata-rata digabungkan, Malaysia berada di peringkat 3. Malaysia sudah memiliki iklim kemudahan berusaha yang baik, namun tetap perlu dipertahankan dan ditingkatkan lagi. Tetapi dari sudut tarif Pajak Penghasilan rata-rata, Malaysia masih perlu mempertimbangkan penyesuaian tarif Pajak Penghasilan. Untuk tarif Pajak Penghasilan Orang Pribadi, Malaysia perlu mempertimbangkan menurunkan batas atas tarif Pajak Penghasilan Marginal Orang Pribadi dari saat ini sebesar 28\% menjadi tarif antara 20\%-25\%, mengingat beberapa negara di ASEAN menggunakan tarif $25 \%$ ke bawah. Sedangkan untuk tarif Pajak Penghasilan Badan, Malaysia dapat mempertimbangkan untuk menurunkannya dari tarif saat ini sebesar $24 \%$ menjadi sekitar $20 \%$ atau kurang, karena Singapura yang bisa dijadikan benchmarking saat ini hanya menerapkan tarif sebesar $17 \%$. Mengingat bahwa iklim kemudahan berusaha Malaysia yang sudah sangat baik, walaupun dari sudut tarif Pajak Penghasilan rata-rata masih belum terlalu kompetitif, tetapi jumlah arus masuk Foreign Direct Investment seharusnya bisa lebih besar dari yang direalisasi saat ini.

\section{Filipina}

Filipina dalam peringkat keberhasilan menarik arus masuk Foreign Direct Investment berada di peringkat 5 dari seluruh negara-negara ASEAN. Bila dilihat dari capaian arus masuk Foreign Direct Investment, hasil ini belum termasuk baik sekali. Namun jika dihubungkan dengan peringkat kemudahan berusaha yang 
hanya berada di peringkat 7 , peringkat tarif Pajak Penghasilan rata-rata yang hanya berada pada peringkat 9, dan gabungan dari peringkat kemudahan berusaha dan peringkat tarif Pajak Penghasilan rata-rata yang hanya berada di peringkat 7, hasil yang diperoleh Filipina dalam menarik arus masuk Foreign Direct Investment sudah termasuk baik. Memang Filipina harus berusaha lebih baik lagi guna menarik arus masuk Foreign Direct Investment yang lebih besar. Filipina dapat memperbaiki iklim kemudahan berusaha dengan usaha-usaha yang dapat mendukung iklim usaha yang kondusif, dengan harapan peringkat kemudahan berusaha dari Filipina bisa menjadi lebih baik lagi.

Di samping itu Filipina juga harus mempertimbangkan untuk menyesuaikan tarif Pajak Penghasilan yang diterapkan. Untuk tarif Pajak Penghasilan Orang Pribadi, Filipina dapat mempertimbangkan untuk menurunkan batas atas tarif Pajak Penghasilan Marginal Orang Pribadi dari tarif sebesar 35\% menjadi tarif antara 20\%-25\%, mengingat beberapa negara di ASEAN menggunakan tarif $25 \%$ ke bawah. Sedangkan untuk tarif Pajak Penghasilan Badan, Filipina perlu mempertimbangkan agar tarif yang digunakan saat ini sebesar 30\% dapat diturunkan menjadi sekitar $20 \%$ atau kurang untuk menyesuaikan dengan tarif yang diberlakukan oleh sebagian besar negara-negara ASEAN.

\section{Thailand}

Thailand dalam peringkat mendapatkan arus masuk Foreign Direct Investment berada pada peringkat 6 dari 11 negara ASEAN. Di antara negaranegara ASEAN, Thailand berada di peringkat 3 dari kemudahan berusaha, peringkat 5 tarif Pajak Penghasilan rata-rata, dan peringkat 3 gabungan peringkat kemudahan berusaha dan peringkat tarif Pajak Penghasilan rata-rata. Data ini menunjukkan bahwa arus masuk Foreign Direct Investment masih belum maksimal, mengingat bahwa peringkat kemudahan berusaha sangat baik. Dalam hal ini perlu dilakukan evaluasi dan perbaikan terhadap usaha-usaha untuk menarik arus masuk Foreign Direct Investment. Di samping itu dari sudut tarif Pajak Penghasilan, Thailand perlu mempertimbangkan untuk melakukan peninjauan kembali, khususnya untuk tarif Pajak Penghasilan Orang Pribadi. Thailand dapat mempertimbangkan untuk menurunkan batas atas tarif Pajak Penghasilan Marginal Orang Pribadi dari 35\% menjadi tarif antara 20\%-25\%, karena beberapa negara lain di ASEAN menggunakan tarif antara 20\%-25\%. Untuk tarif Pajak Penghasilan Badan, Thailand sudah menawarkan tarif yang sangat kompetitif sebesar 20\%, namun dapat mempertimbangkan untuk menurunkannya lagi. Untuk iklim kemudahan berusaha, Thailand dapat tetap berusaha meningkatkannya lagi agar bisa menjadi lebih baik dengan benchmarking pada Singapura.

\section{Kamboja}

Kamboja berada di peringkat 7 dari seluruh negara-negara ASEAN dalam memperoleh arus masuk Foreign Direct Investment. Di antara semua negaranegara ASEAN, Kamboja berada di peringkat 8 untuk kemudahan berusaha, di peringkat 3 untuk tarif Pajak Penghasilan rata-rata, dan di peringkat 4 untuk gabungan peringkat kemudahan berusaha dan peringkat tarif Pajak Penghasilan 
rata-rata. Dalam hal ini Kamboja dapat melakukan berbagai usaha untuk meningkatkan iklim kemudahan berusaha di negaranya, agar dapat menaikkan peringkat kemudahan berusaha, dan menarik investor asing yang lebih banyak lagi guna menanamkan modalnya dalam bentuk Foreign Direct Investment. Kamboja menetapkan batas atas tarif Pajak Penghasilan Marginal Orang Pribadi dan tarif Pajak Penghasilan Badan sama-sama sebesar 20\%. Dari sudut tarif Pajak Penghasilan, Kamboja sudah mengimplementasikan tarif Pajak Penghasilan yang sangat kompetitif, baik untuk tarif Pajak Penghasilan Orang Pribadi maupun tarif Pajak Penghasilan Badan.

\section{Myanmar}

Myanmar dalam peringkat keberhasilan negara-negara ASEAN dalam menarik arus masuk Foreign Direct Investment berada di peringkat 8, sehingga Myanmar harus banyak berbenah lagi agar arus masuk Foreign Direct Investment yang diperoleh dapat meningkat secara signifikan. Untuk iklim kemudahan berusaha, Myanmar harus berusaha melakukan berbagai usaha perbaikan lagi agar peringkat kemudahan berusaha yang saat ini masih di peringkat 10 dapat ditingkatkan. Dari sudut tarif Pajak Penghasilan rata-rata, Myanmar berada di peringkat 5 yang termasuk peringkat di tengah-tengah. Jika dilihat dari tarif Pajak Penghasilan yang diterapkan, baik untuk tarif Pajak Penghasilan Orang Pribadi maupun tarif Pajak Penghasilan Badan, Myanmar tidak menerapkan tarif yang tinggi, tetapi juga tidak terlalu rendah. Untuk batas atas Tarif Pajak Penghasilan Marginal Orang Pribadi dan tarif Pajak Penghasilan Badan Myanmar sama-sama menetapkan tarif sebesar 25\%. Dalam usaha meningkatkan arus masuk Foreign Direct Investment yang lebih besar, Myanmar dapat mempertimbangkan untuk menurunkan batas atas tarif Pajak Penghasilan Marginal Orang Pribadi dan tarif Pajak Penghasilan Badan.

\section{Laos}

Laos menduduki peringkat 9 diukur dari keberhasilan negara-negara ASEAN dalam menarik arus masuk Foreign Direct Investment. Laos menduduki peringkat 9 dari segi kemudahan berusaha, berada di peringkat 4 dari sudut tarif Pajak Penghasilan rata-rata, dan berada di peringkat 5 dari gabungan kemudahan berusaha dan tarif Pajak Penghasilan rata-rata. Berada dalam situasi demikian sudah seharusnya Laos melakukan berbagai usaha untuk meningkatkan jumlah arus masuk Foreign Direct Investment. Untuk dapat bersaing dengan sesama negara-negara ASEAN lainnya, Laos harus melakukan berbagai perbaikan guna memenuhi indikator-indikator kemudahan berusaha, agar skor kemudahan berusahanya bisa meningkat. Hal ini akan dapat meningkatkan minat investor untuk menanamkan modalnya dalam bentuk Foreign Direct Investment ke Laos. Dari sudut tarif Pajak Penghasilan, seperti halnya Myanmar, Laos juga tidak menerapkan tarif yang tinggi, dan juga tidak rendah. Laos menerapkan batas atas tarif Pajak Penghasilan Marginal Orang Pribadi dan tarif Pajak Penghasilan Badan sama-sama sebesar 24\%. Dalam hal ini Laos dapat mempertimbangkan untuk menurunkan batas atas tarif Pajak Penghasilan Marginal Orang Pribadi dan tarif Pajak Penghasilan Badan. 


\section{Brunei}

Brunei menduduki peringkat terakhir di luar Timor Leste ditinjau dari keberhasilan menarik arus masuk Foreign Direct Investment ke negaranya. Hal ini sebenarnya sangat kontras sekali jika dibandingkan dengan keberhasilan dari Brunei menciptakan iklim kemudahan berusaha dan penetapan tarif Pajak Penghasilan rata-rata yang rendah. Brunei menduduki peringkat 4 dari peringkat kemudahan berusaha, peringkat 1 dari tarif Pajak Penghasilan rata-rata, dan peringkat 2 dari gabungan peringkat kemudahan berusaha dan peringkat tarif Pajak Penghasilan rata-rata. Walaupun sudah berada di peringkat 4 kemudahan berusaha, Brunei harus tetap memperbaiki semua indikator yang berhubungan dengan kemudahan berusaha agar peringkat kemudahan berusahanya menjadi lebih baik lagi. Dari sudut tarif Pajak Penghasilan rata-rata, Brunei tidak perlu lagi melakukan perubahan, karena tarif Pajak Penghasilan yang diterapkan sudah sangat rendah. Di samping itu untuk meningkatkan jumlah arus masuk Foreign Direct Investment, harus dilakukan evaluasi menyeluruh mengenai strategi yang digunakan guna menarik investor asing.

\section{SIMPULAN}

Setiap negara, baik negara maju maupun negara berkembang membutuhkan arus masuk Foreign Direct Investment untuk membantu memacu percepatan perputaran ekonomi nasional dan pembangunan berkelanjutan. Setiap negara akan berpacu memberikan penawaran yang menarik agar investor asing mau menanamkan modalnya dalam bentuk Foreign Direct Investment. Ada beberapa tolak ukur yang dipakai investor asing untuk menanamkan modalnya dalam bentuk Foreign Direct Investment di suatu negara, antara lain kemudahan untuk berusaha yang di dalamnya termasuk tarif Pajak Penghasilan.

Kebutuhan akan arus masuk Foreign Direct Investment juga terjadi pada negara-negara di kawasan Asia Tenggara yang tergabung dalam ASEAN. Negaranegara ASEAN berlomba untuk menarik arus masuk Foreign Direct Investment yang sebesar-besarnya. Di antara sesama negara-negara ASEAN, Singapura merupakan negara yang paling berhasil dalam menarik arus masuk Foreign Direct Investment, di mana 59,10\% arus masuk Foreign Direct Investment di negaranegara ASEAN merupakan arus masuk Foreign Direct Investment Singapura. Keberhasilan Singapura di dalam menarik arus masuk Foreign Direct Investment sejalan dengan kesuksesan Singapura dalam menyediakan iklim kemudahan berusaha dan tarif Pajak Penghasilan rendah yang diimplementasikan.

Rata-rata indeks kemudahan berusaha di negara-negara ASEAN sebesar 64,63. Tarif Pajak Penghasilan Orang Pribadi negara-negara ASEAN batas bawahnya antara 0\%-5\%, dan batas atasnya rata-rata sebesar 28,22\%. Sedangkan tarif Pajak Penghasilan Badan rata-rata negara-negara ASEAN sebesar 22,05\%. Batas atas tarif Pajak Penghasilan Orang Pribadi rata-rata negara-negara ASEAN masih cukup tinggi, namun tarif Pajak Penghasilan Badan rata-rata negara ASEAN sudah cukup moderat, karena sudah lebih rendah dari tarif Pajak Penghasilan Badan rata-rata dunia sebesar 23,85\%. 


\section{SARAN}

Negara-negara ASEAN di luar Singapura masih harus melakukan banyak pembenahan untuk meningkatkan iklim kemudahan berusaha dan penyesuaian tarif Pajak Penghasilan. Negara-negara ASEAN yaitu Filipina, Kamboja, Laos, dan Myanmar yang memiliki indeks kemudahan berusaha di bawah rata-rata indeks kemudahan berusaha negara-negara ASEAN sebesar 64,63 harus melakukan berbagai usaha untuk memperbaiki iklim kemudahan berusaha di negaranya masing-masing.

Sedangkan negara-negara ASEAN yaitu Filipina, Indonesia, Thailand, dan Vietnam yang memiliki batas atas tarif Pajak Penghasilan Orang Pribadi lebih tinggi dari rata-rata batas atas tarif Pajak Penghasilan Orang Pribadi negaranegara ASEAN sebesar 28,22\% dapat mempertimbangkan untuk menurunkan batas atas tarif Pajak Penghasilan Orang Pribadi di masing-masing negara tersebut. Kemudian negara-negara ASEAN yaitu Filipina, Laos, Malaysia, dan Myanmar yang memiliki tarif Pajak Penghasilan Badan lebih tinggi dari rata-rata tarif Pajak Penghasilan Badan negara-negara ASEAN sebesar 22,05\% dapat mempertimbangkan untuk menurunkan tarif Pajak Penghasilan Badan di masingmasing negara tersebut.

\section{DAFTAR PUSTAKA}

Abdin, Md. Joynal. 2019. Ease of Doing Business Index.

ASEAN Secretariat. 2020. ASEAN Key Figures 2020. ASEAN Secretariat Community Relations Division.

Asen, Elke. 2020. Corporate Tax Rates Around The World. Fiscal Fact No. 735 Tax Foundation.

Bayraktar, Nihal. 2013. Foreign Direct Investment and Investment Climate. Procedia Economics and Finance. Vol. 5, pp. 83-92.

Bonu, N. S. and Pedro Motau P.. 2009. The Impact of Income Tax Rates (ITR) on The Economic Development of Botswana. Journal of Accounting and Taxation, Vol. 1, No. 1, pp. 8-22.

Djankov, Simeon, Tim Ganser, Caralee McLiesh, Rita Ramalho, and Andrei Shleifer. 2010. The Effect of Corporate Taxes on Investment and Entrepreneurship. American Economic Journal: Macroeconomics, Vol. 2, No. 3, pp. 31-64.

Esteller-Moré, Alejandro, Leonzio Rizzo, and Riccardo Secomandi. 2020. The heterogenous impact of taxation on FDI: A note on Djankov et al. (2010). Economics Letters, Vol. 186.

Lejárraga, Iza and Alexandros Ragoussis. 2018. Beyond Capital: Monitoring Development Outcomes of Multinational Enterprises. Policy Research Working Paper. WPS8686. International Finance Corporation, World Bank Group. 
OECD. 2007. Tax Effects on Foreign Direct Investment - No. 17, Executive Summary.

OECD. 2019. FDI Qualities Indicators: Measuring The Sustainable Development Impacts of Investment.

OECD. 2020. The Global Revenue Statistics Database.

Shira, Dezan \& Associates. 2018. The 2018/19 ASEAN Tax Comparator. ASEAN Briefing, Issue 10.

UNCTAD. 2020. 2020 Handbook of Statistics. Geneva: United Nations.

World Bank. 2020. Doing Business 2020: Comparing Business Regulation in 190 Economies, Washington DC: International Bank for Reconstruction and Development/The World Bank 1818 H Street NW.

World Bank-a. 2020. https://data.worldbank.org/indicator/GC.REV.XGRT.GD. $Z S$.

World Bank-b. 2020. https://data.worldbank.org/indicator/GC.TAX.TOTL.GD. $Z S$. 